\title{
Influence of a cylindrical crosshead on shear bond testing of composite-tooth interfaces
}

\author{
Chris S. IVANOFF ${ }^{1,2}$, Timothy L. HOTTEL ${ }^{3}$ and Franklin GARCIA-GODOY ${ }^{1}$ \\ ${ }^{1}$ Department of Bioscience Research, College of Dentistry, The University of Tennessee Health Science Center, 875 Union Avenue, Memphis, TN \\ 38163, USA \\ ${ }^{2}$ Faculty of Dental Medicine, Medical University of Sofia, No. 1 'Sveti Georgi Sofiiski' Blvd., Sofia 1431, Bulgaria \\ ${ }^{3}$ Department of Prosthodontics, College of Dentistry, The University of Tennessee Health Science Center, 875 Union Avenue, Memphis, TN 38163 , \\ USA \\ Corresponding author, Chris S. IVANOFF; E-mail: civanoff@uthsc.edu
}

\begin{abstract}
The effect of a cylindrical crosshead on shear bond strength of composite to dentin was assessed by finite element analysis (FEA) after shear bond testing thirty mandibular molars restored with composite cylinders (Tetric EvoCeram-3 mm diameter) perpendicular to conditioned dentin. Cross-sectional geometric models were created with quadrilateral linear plane stress elements. Stress distributions for normal, shear, and major principal stresses were plotted. Mean shear bond strength for the experimental group was $23.9 \mathrm{MPa}( \pm 4.54)$, about $15-75 \%$ higher than values reported with other methods. FEA showed localized 'hot spots' $( \pm 16-20 \mathrm{MPa})$ at the corners of the base of the adhesive layer under a $20 \mathrm{~N}$ vertical load. Principal stresses across the composite-dentin interface were lower $( \pm 12-16 \mathrm{MPa})$, but significantly homogenous, approximating closely the nominal strength value. With uniform stress distributions across the adhesive layer, FEA confirmed that a cylindrical crosshead may be an optional tool to improve shear bond testing of dental materials.
\end{abstract}

Keywords: Cylindrical crosshead, Shear bond strength, Finite element analysis

\section{INTRODUCTION}

Bond strength values assess the efficacy of bonding restorative materials to dentin ${ }^{11}$. In shear bond testing, two materials joined together by an adhesive agent are loaded in shear until the bond fails ${ }^{2}$. Macro-bond strengths can be measured by shear, tensile, or pushout tests ${ }^{3}$. Though simple to perform, these tests have drawbacks ${ }^{4,5)}$, including issues related to the dentin substrate, composite, and bonding area ${ }^{6)}$, storage conditions of the bond assemblies, and test design ${ }^{2}$. The crosshead chosen to apply the shear force can also be a factor. Knife edges, points, as well as wire loops are currently among the more popular tools employed in this type of testing.

In tensile bond testing, a force is applied to either side of a test specimen, which actively or passively is held by a gripping device ${ }^{7}$. In comparison to shear tests, forces across the interface are more homogeneous and yield maximum principal stress values that most closely approximate the actual nominal strength ${ }^{5,8)}$. However, the tests are technique sensitive and require specialized tweezer tips to pull the substrate and adhesive layer apart ${ }^{2)}$. Specimen alignment is also critical to avoid uneven stress distribution upon the specimen during loading ${ }^{7}$.

When the shear device applies forces on larger contact areas such as with the wire loop ${ }^{9}$, stainless steel tape ${ }^{10)}$ and the Ultradent device ${ }^{11)}$, higher shear

Color figures can be viewed in the online issue, which is available at J-STAGE.

Received Sep 21, 2017: Accepted Dec 28, 2017

doi:10.4012/dmj.2017-348 JOI JST.JSTAGE/dmj/2017-348 bond strength values are expected due to a more even distribution of the forces ${ }^{12}$. However, bond strength values can be affected by specimen size, loading length, adhesive layer thickness, and loading site ${ }^{2}$. In comparison to a knife edge, the use of a wire-loop may decrease stress concentration at the adhesive interface, but finite element analysis (FEA) has shown this method grossly underestimates bond strength values ${ }^{7,12)}$.

Micro-tensile bond tests are an alternative which allow for testing of small areas, thus permitting a regional mapping or depth profiling of different substrates and preparing multiple specimens from the same tooth ${ }^{13)}$. However, the method is not easily applied because of small sample size and brittleness ${ }^{9,12}$. Micro-tensile bond testing is subject further to the cross-sectional shape and surface area ${ }^{14,15)}$, cutting speed ${ }^{16)}$, and geometry of the samples, as well as the means of attachment and testing device ${ }^{17)}$. The shear load must also be applied precisely at the bonded interface to avoid subjecting the cylinder to rotation or bending rather than shear tension ${ }^{7,12}$. A relatively thicker adhesive layer in microshear tests, among other reasons, concentrates stresses which influence the maximum load, thereby rendering micro-tensile tests less accurate than shear tests ${ }^{2}$. Single lap shear bond strength tests as described by Watanabe et al. ${ }^{18)}$ are an effective alternative that can align tooth specimens to shear direction by loading the test sections parallel to the adhesive interface formed between the dentin and test material. The design of the single plane shear test assembly supports the restorative material and does not allow line or point contact during 

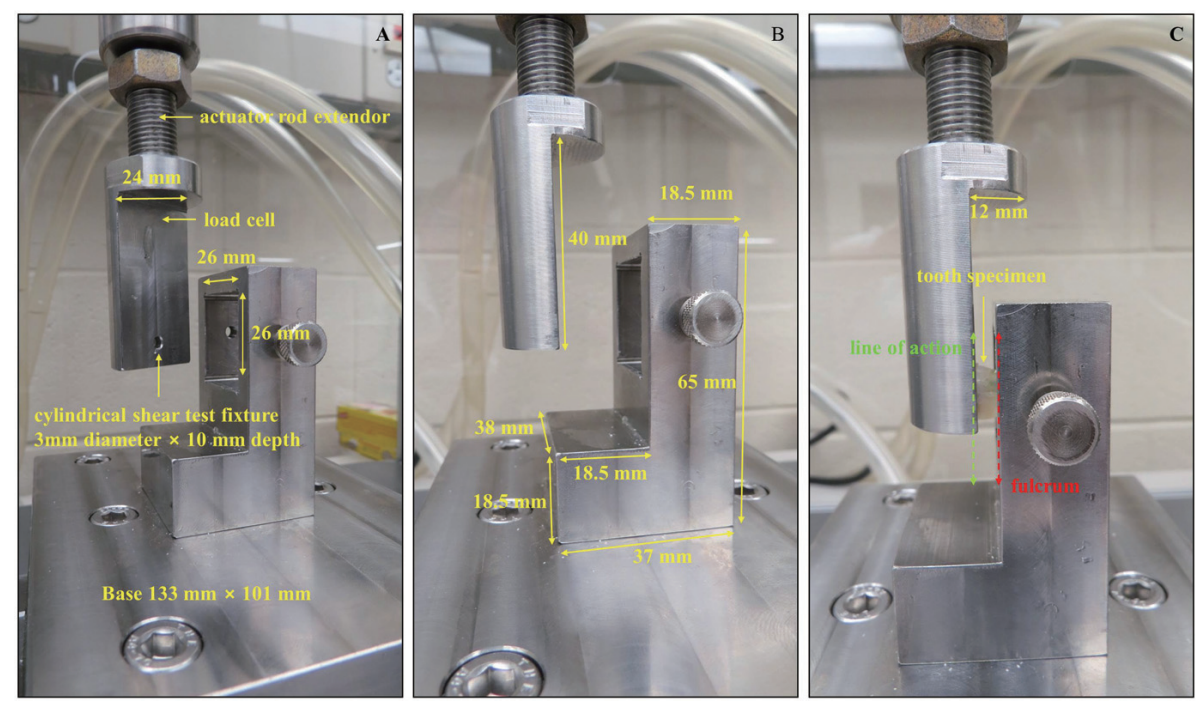

Fig. 1 (A) The assembly is comprised of an upper and lower member. An actuator rod extender connects to the load cell via a $1 / 2$ "-20 thread screw which allows for vertical adjustment. The load cell consists of a cylindrical shear testing fixture (crosshead) which is $3 \mathrm{~mm}$ in diameter to engage a composite restoration (also $3 \mathrm{~mm}$ in diameter) bonded to a tooth specimen. (B) The tooth is mounted in an acrylic block prepared with $1 \mathrm{in}^{2}\left(26 \mathrm{~mm}^{2}\right)$ teflon molds, which then is intimately positioned for testing in a corresponding $1 \mathrm{in}^{2}$ opening in the lower member and locked into place with an 8-32 knurled-head thumb screw. (C) The metal holders are adjustable so that both the fulcrum and line-of-action can be aligned at various positions. A carriage slide with one degree of freedom is attached to the base of the lower member to facilitate alignment of the cylindrical restoration with the opposing cylindrical shear testing fixture. The acrylic block, in turn, can slide in the lower member at various positions to facilitate alignment of the fulcrum with either the tooth-composite interface or the CEJ as would occur intraorally. The samples are subjected to a shear force (plane stress) on the adhesive interface by stretching vertically on the specimen until the restoration fails.

application of load ${ }^{19,20)}$.

Given the importance of in vitro mechanical tests to evaluate and compare bond strengths of adhesive systems to enamel and dentin, the purpose of this study is to assess a modified test design for shear bond testing that may incorporate the relative simplicity and predictability of shear bond strength tests, while overcoming the difficulties of tensile bond strength tests in aligning the specimen in the testing machine without creating deleterious stress distribution. A cylindrical crosshead (Fig. 1) is, therefore, evaluated for shear bond strength testing of composite-tooth interfaces along with a lap shear jig that integrates the whole biomechanical unit into testing to allow the mechanical behavior of the restored tooth to be further evaluated as a response variable.

After measuring the shear bond strength of a composite restoration (Tetric EvoCeram) bonded to a $7.06 \mathrm{~mm}^{2}$ circular area of dentin on human molars, a FEA assesses whether a cylindrical crosshead may distribute loading forces homogenously across restoration-tooth interfaces, while approximating more closely nominal strength values. It is postulated that a cylindrical crosshead in the proposed jig design may transfer the applied shear force homogenously across the dentinadhesive layer to yield higher shear bond strength than previously reported by other investigators using different test setups and crossheads. With uniform distribution of stresses across the adhesive layer, the FEA will confirm that a cylindrical crosshead can be effectively used as an optional macro-shear test.

\section{MATERIALS AND METHODS}

\section{Shear bond testing jig}

The lap shear testing jig measures the shear bond strength of restorative materials by applying force at the location of the adhesive layer while integrating the whole tooth into testing (Fig. 2). The assembly consists of two offset joggle lap metal holders and uses a cylindrical crosshead to apply the load. The restored tooth is mounted into one holder, while the restoration is held by the other. The adjustable metal holders are easily configured to align the centerline of the grip assembly 


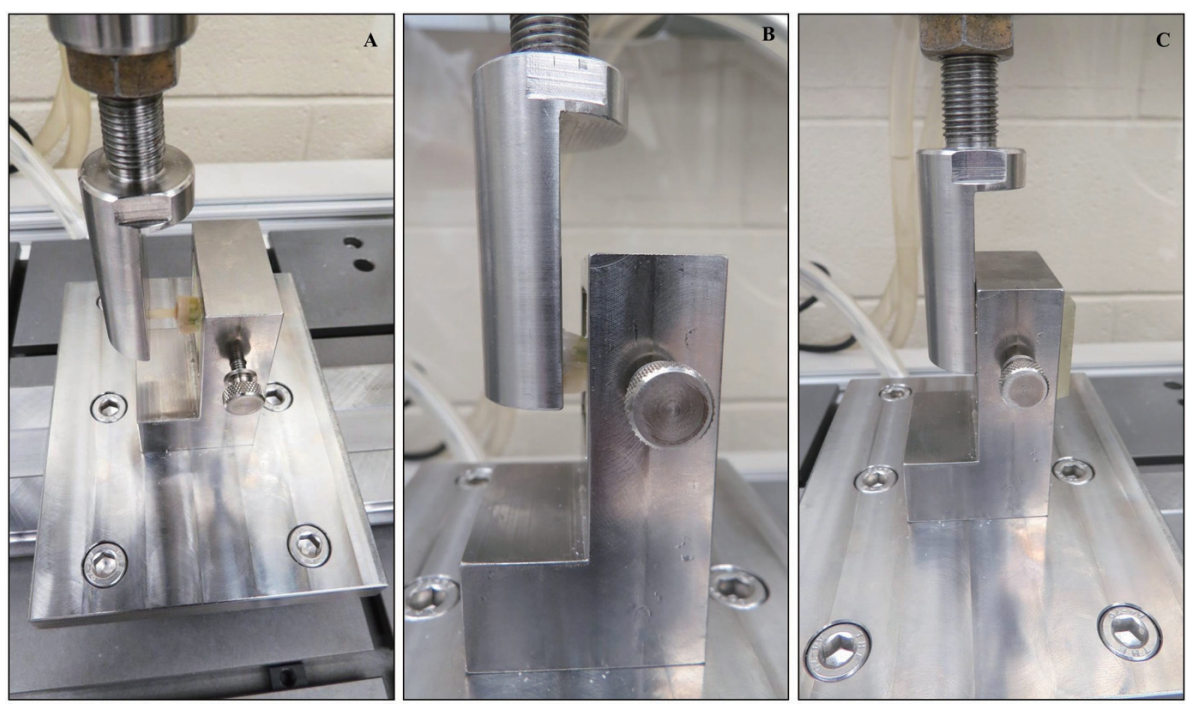

Fig. 2 (A) The jig is shown in a lab setup with a tooth specimen locked into one holder, while the composite button on the occlusal surface of the tooth engages a $3 \mathrm{~mm}$ hole in the other holder. (B) In this set up, the fulcrum is set at the CEJ of the mounted tooth specimen and offset from the line of action at the tooth-restoration interface. In this orientation, the entire biological unit can be tested as a response variable under conditions mimicking mastication. (C) Lab setup for shear bond test of an encapsulated cylindrical restoration at the dentin-composite interface (button on dentin floor) loaded via lap joint when the line-of-action starts at the adhesion layer.

with the adhesive bond at the bottom of the restoration. Self-tightening vise grips are used to prevent slipping. The assembly adapts to a commercially available servo-hydraulic mechanical testing machine which measures shear bond strength by stretching vertically on the specimen at the desired crosshead speed until the restoration fails. The tensile force is applied at a controlled rate which is proportional to the entire adhesive surface area.

\section{Shear bond testing}

Thirty virgin mandibular third molars, with similar crown size and without caries were used for the study. The teeth were extracted for orthodontic reasons, examined at $10 \times$ magnification under an optical microscope (SZ-TP Olympus, Tokyo, Japan) to check for cracks and other defects, and stored in $0.5 \%$ chloramine-T at $4^{\circ} \mathrm{C}$ until used. Bond strengths were measured less than six months after extraction as per ISO technical specification $11405^{2}$. The cusp tips of each tooth were reduced with a double-faced diamond disc No. 7011 (KGSorensen, São Paulo, Brazil), producing a flattened occlusal dentin surface. The teeth were then sanded with 180, 320, and 600 grit silicon carbide paper for $60 \mathrm{~s}$. The occlusal surface of each tooth was etched with $37 \% \quad \mathrm{H}_{3} \mathrm{PO}_{4}$ and coated with ExciTE adhesive (Ivoclar Vivadent, Amherst, NY, USA). Tygon tubing was attached to the occlusal surface of each restoration and filled with Tetric EvoCeram composite (Ivoclar Vivadent) according to the manufacturer's recommendations.
The tygon tube was removed after curing, resulting in cylinders of resin composite with cross-sectional diameter and height of $3 \mathrm{~mm}$ respectively.

All the specimens were stored in distilled water for $24 \mathrm{~h}$ at $37^{\circ} \mathrm{C}$ to simulate intraoral conditions until testing ${ }^{1)}$. The specimens were then subjected to shear bond testing in a servo-hydraulic testing machine (INSTRON 5900, INSTRON, Norwood, MA, USA). An ad hoc assembly of two metal holders was manufactured to hold all dental elements (Fig. 1). Each tooth specimen was mounted into one holder, while the composite button engaged a $3 \mathrm{~mm}$ cylindrical crosshead in the other holder. The teeth were then fixed in the holders with orthodontic resin to avoid any sliding during testing. The centerline of the grip assembly was aligned with the dentin-adhesive bond layer at the bottom of the composite button ${ }^{21)}$. The samples were then subjected to a shear force at a crosshead speed of $0.5 \mathrm{~mm} / \mathrm{min}$. by stretching vertically on the specimen until the restorations failed (Fig. 2(c)). All the procedures were conducted at room temperature. The shear bond strength was then calculated in units of $\mathrm{MPa}$ after measuring the cross-sectional area at the fracture site according to the formula: $\tau=\mathrm{F} / \mathrm{A}(\mathrm{N} /$ $\mathrm{mm}^{2}=\mathrm{MPa}$ ). Mean shear bond strengths and standard deviations were calculated. A single examiner evaluated failure modes using a microscope (SZ-TP Olympus, Tokyo, Japan) at 10× magnification. Failure modes were classified as adhesive failure, cohesive failure, or mixed adhesive/cohesive failure ${ }^{2)}$. 


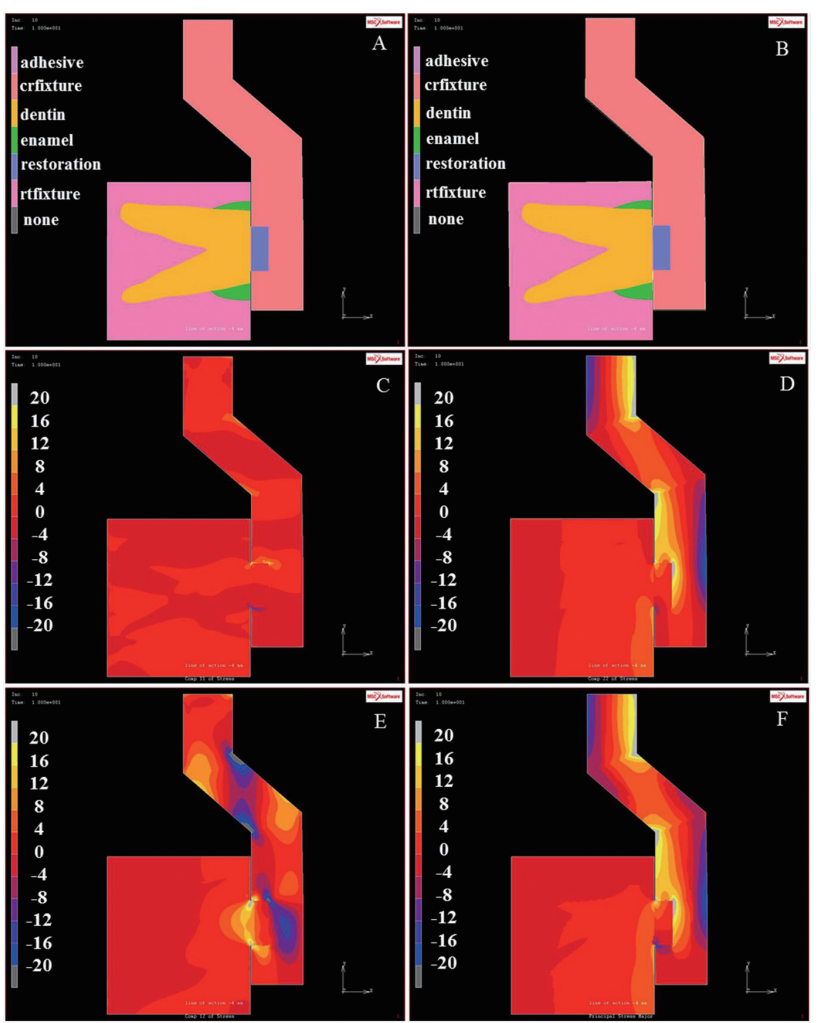

Fig. 3 (A) Shear bond strength test model for the dentincomposite interface of an encapsulated cylindrical restoration (button on dentin floor) loaded via lap joint when the line-of-action starts at the adhesion layer (line of the button bottom) (B) Image shows the deformation at $20 \times$ exaggeration for $20 \mathrm{~N}$ loading; (C) the distributions of the two normal stress components (stress in $\mathrm{x}$-direction, which is horizontal; (D) stress in y-direction, which is vertical); (E) the xy-shear stress and; (F) the major principal stress (the major value of the three principal stress values). Stress scales are -20 to 20 $\mathrm{MPa}$, except for the shear stresses, where the scale was reduced to -5 to $5 \mathrm{MPa}$ to increase resolution.

\section{FEA}

FEA was conducted using MSC Marc and Mentat software (MSC Software, Palo Alto, CA, USA). Crosssectional geometric models were manually created in Mentat with quadrilateral linear plane stress elements, which are two-dimensional elements, and featured the various components of the experimental design and samples (Figs. 3-5). The number of elements ranged between 2,042 and 2,419 and the number of nodes between 2,154 and 2,541. Cross-sectional models, which show the stresses and strains in the cross-section of a structure, are often used to demonstrate general stress distributions. The elastic modulus and Poisson's ratios applied for different components are listed in Table $1^{22-26)}$. All properties were considered homogeneously distributed, isotropic, and linear-elastic. Although dentin and enamel properties can vary throughout a tooth, these variations are relatively small compared to
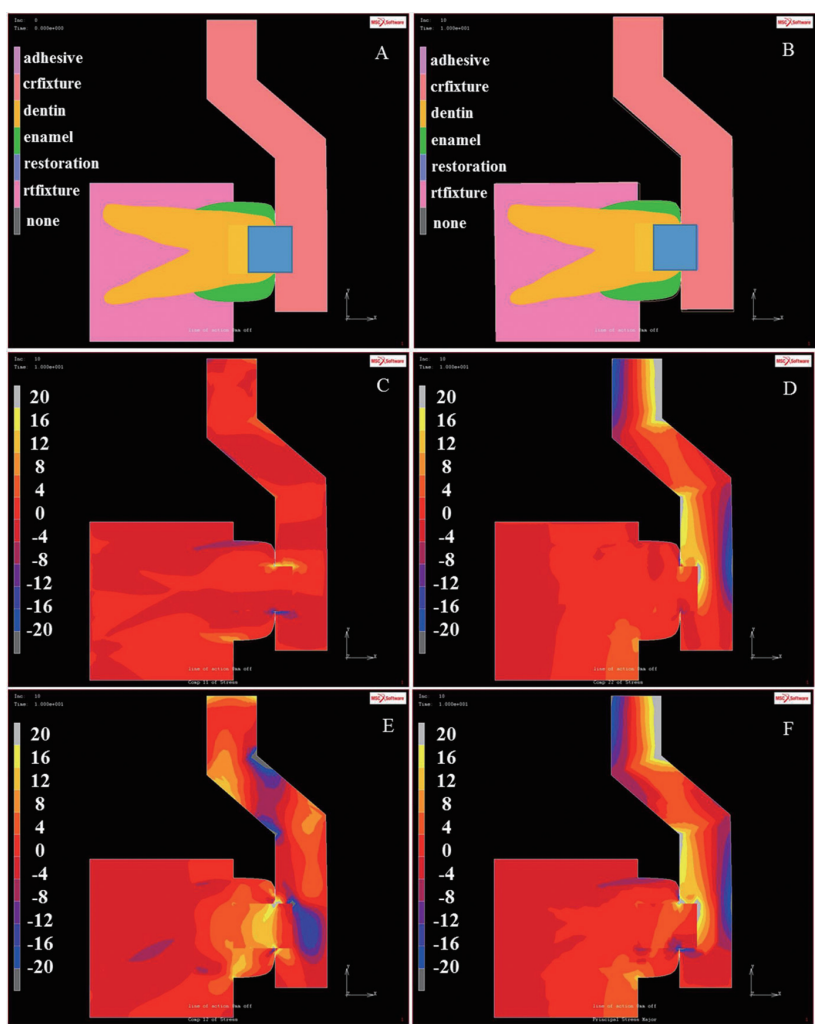

Fig. 4 (A) Tooth with restoration loaded via a lap joint when embedding is pulled up to the height of the CEJ. The 'line-of-action' is the level of the adhesive layer. (B) Deformation at 20× exaggeration for $20 \mathrm{~N}$ loading. (C) The distributions of the normal stress components in x-direction (horizontal); (D) stress in $y$-direction (vertical); (E) the xy-shear stress and; (F) the major principal stress. Stress scales are the same as previously ( -20 to $20 \mathrm{MPa}$ ), except for the shear stresses, where the scale was reduced to -5 to $5 \mathrm{MPa}$ to increase resolution.

their general properties. The homogeneity assumption can therefore be expected to have little effect on the general stress distribution. The samples were modeled as fixed in a resin block. The bottom of the resin block was rigidly fixed, simulating the lower section of the lap joint fixture (Fig. 2). The restoration was perfectly bonded (no gaps) to the tooth structure and in the steel lap-joint socket. The top surface of the upper segment of the steel lap-joint was rigidly fixed in a horizontal direction, while vertical movements were left free to move up or down. A vertical tensile load was distributed over the upper surface. The tensile load was increased from 0 to $20 \mathrm{~N}$ in 20 increments of $1 \mathrm{~N}$. Stress distributions were calculated and reported at the last increment, where the applied tensile force was $20 \mathrm{~N}$. Stress distributions for normal stresses ( $\mathrm{x}$ in horizontal direction and y in vertical direction), shear stresses, and the major principal stresses (highest absolute value of the principal stresses) were plotted. Deformation models were plotted at $20 \times$ to visualize sample deformation. 
Table 1 Elastic modulus values and Poisson's ratios for the different materials applied in the FEA

\begin{tabular}{lcc}
\hline \multicolumn{1}{c}{ Material } & Elastic Modulus (GPa) & Poisson's Ratio \\
\hline Enamel & 84 & 0.3 \\
Dentin & 21 & 0.24 \\
Restoration & 12 & 0.24 \\
Bonding Agent & 5 & 0.3 \\
Steel & 210 & 0.3 \\
Resin & 5 & 0.3 \\
\hline
\end{tabular}

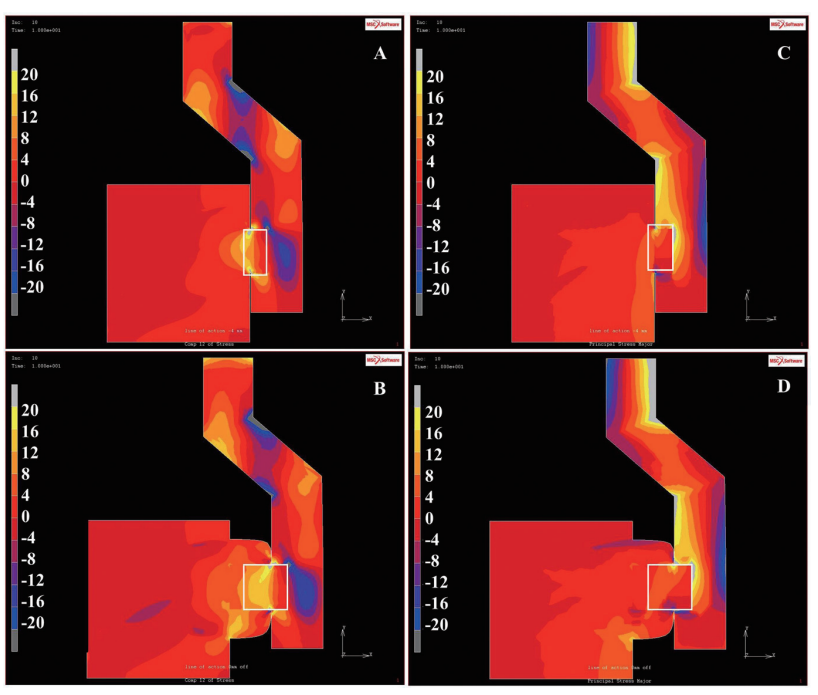

Fig. 5 A comparison of 'xy' shear stress for: (A) an encapsulated cylindrical restoration with the line of action at the restoration floor to (B) a restoration with intact cavity walls and the fulcrum at the CEJ; (C) The 'major principle' stress for a composite button with the line of action at the restoration floor is compared to a (D) restoration with intact cavity walls at fulcrum at the CEJ.

\section{RESULTS}

The mean shear bond strength of composite restorations filled with ExciTE adhesive and Tetric EvoCeram composite was determined to be $23.9 \mathrm{MPa}(\mathrm{SD} \pm 4.54)$. The mode of failure in all cases (100\%) was adhesive. Images of the FEA analysis are presented in Figs. 3-5. The FEA models show the different components: dentin and enamel; bonding agent and composite; metal bracket for pulling on the restoration; and resin embedding material around the root. The resin was rigidly fixed at the bottom as shown in the design, while pulling straight up on the opposing metal fixture. The applied load was $20 \mathrm{~N}$. This load is arbitrary because stresses scale with it, while distribution patterns stay the same unless deformation becomes excessive.

The models in Fig. 3 depict a tooth with a composite button loaded via a lap joint when the embedding is pulled up to the height of the adhesive layer. The encapsulated cylindrical restoration (button on dentin floor) was loaded with a force via the lap joint along the line-of-action at the adhesion layer (line of the button bottom). The distributions of the two normal stress components (stress in $\mathrm{x}$-direction, which is horizontal; stress in y-direction, which is vertical), the xy-shear stress, and the major principal stress (the major value of the 3 principal stress values) are shown in images labeled 'x-stress' (C), 'y-stress' (D), xy-shear' (E), and 'major-principal stress' (F), respectively. Stress scales are -20 to $20 \mathrm{MPa}$, except for shear stresses, where the scale was reduced to -5 to $5 \mathrm{MPa}$ to increase resolution. Image (B) shows the deformation at $20 \times$ exaggeration for $20 \mathrm{~N}$ loading. The elastic moduli for each material are: 5, 21, 84, 5, 12 and $210 \mathrm{GPa}$, respectively (Table 1$)^{22-26)}$. The results showed that stresses across the adhesive interface $( \pm 12-16 \mathrm{MPa})$ were distributed homogenously, with major principal stresses approximating closely the value of the applied force (20 $\mathrm{N} / \mathrm{mm}^{2}$ ). Higher local stress values were measured at the corners of the restoration $\left( \pm 16-20 \mathrm{~N} / \mathrm{mm}^{2}\right)$, but the localized 'hot spots' did not exceed the loading force.

For comparison purposes, stress concentrations were also evaluated in a model which reconfigured the composite button as a class I restoration that was $3 \mathrm{~mm}$ in diameter and $6 \mathrm{~mm}$ in height. The acrylic embedding was pulled down to the CEJ to transfer the fulcrum as it would occur clinically (Fig. 4). A load of $20 \mathrm{~N}$ was then applied to the composite. According to FEA, the highest stresses in this bond test occurred at the restoration margins (Fig. 4(e)), where they could be tensile or compressive depending on the side of the restoration, reaching \pm 20 $\mathrm{MPa}$ under a $20 \mathrm{~N}$ vertical load application. At the bottom of the restoration (across the composite-dentin interface) stresses were lower, between $\pm 4-8 \mathrm{MPa}$ in dentin and $\pm 4-8 \mathrm{MPa}$ in the adhesive layer. The distribution of shear forces mimicked stress concentrations in the occlusal enamel and at the CEJ as would be expected to occur clinically. In dentin, the highest equivalent stresses occurring at the occlusal edges were deflected away from the pulp chamber and transferred to the cervical region of the lingual wall of the molar (Fig. 5). 


\section{DISCUSSION}

Several studies have recently examined the shear bond strength of Tetric EvoCeram composite to human molar dentin using various methods and crossheads ${ }^{13,27-29)}$. However, the fact that all the parameters in these bond strength studies are not standardized makes it difficult to compare results. Studies using mono-beveled chisel crossheads to measure the shear bond strength of Tetric EvoCeram resin composite cylinders (3 $\mathrm{mm}$ in dia., $4 \mathrm{~mm}$ in height) bonded to dentin of human molars, report values ranging from $11.3 \mathrm{MPa}( \pm 2.2 \mathrm{MPa})$ to $18.66 \mathrm{MPa}( \pm 7.77)^{27,28)}$. Flury et al. ${ }^{29)}$ reported a shear bond strength of 20.7 MPa after using a notched head on $4 \mathrm{~mm}$ thick specimens of Tetric EvoCeram composite bonded to dentin surfaces of extracted human molars treated with the adhesive system OptiBond FLS. Shamrani ${ }^{13)}$ evaluated the micro-shear bond strength of a Tetric EvoCeram to dentin of human molar teeth using orthodontic wire loop (diameter $0.20 \mathrm{~mm}$ ) and reported mean micro-shear bond strength values of $13.85 \mathrm{MPa}$ $( \pm 1.2 \mathrm{MPa})$. In our study using a cylindrical crosshead, the mean shear bond strength of a composite restoration
(ExciTE adhesive and Tetric EvoCeram) bonded to dentin was determined to be $23.91 \mathrm{MPa}^{21)}$. The results were about $15 \%$ higher compared to other investigations using a notched crosshead ${ }^{29)}$, on average $60 \%$ higher than reported values using a chisel ${ }^{27,28)}$, and $73 \%$ higher than bond strength values reported after using an orthodontic wire loop ${ }^{13)}$.

Clearly, the choice of crosshead can greatly influence stress distribution in shear testing ${ }^{2,3}$. Compared to a wire loop, using a knife-edge chisel during testing can cause higher stress concentration at the load application area ${ }^{3)}$, while stainless steel tape allows more uniform stress distribution at the bond interface ${ }^{30)}$. Stress distribution in shear tests is also affected by the distance between the point of load application and the bonded interface due to the fulcrum effect ${ }^{11)}$ (Fig. 6). In lap shear (tensile) testing the adhesive layer is pulled apart along the adhesion plane. If the adhesive layer does not break way cleanly from the substrate, failure will occur in the cohesion of either the substrate or the adhesive layer, or both. In our study, all of the failures were adhesive. Distortion away from the plane of adhesion can be minimized with this type of testing since tensile forces can be applied
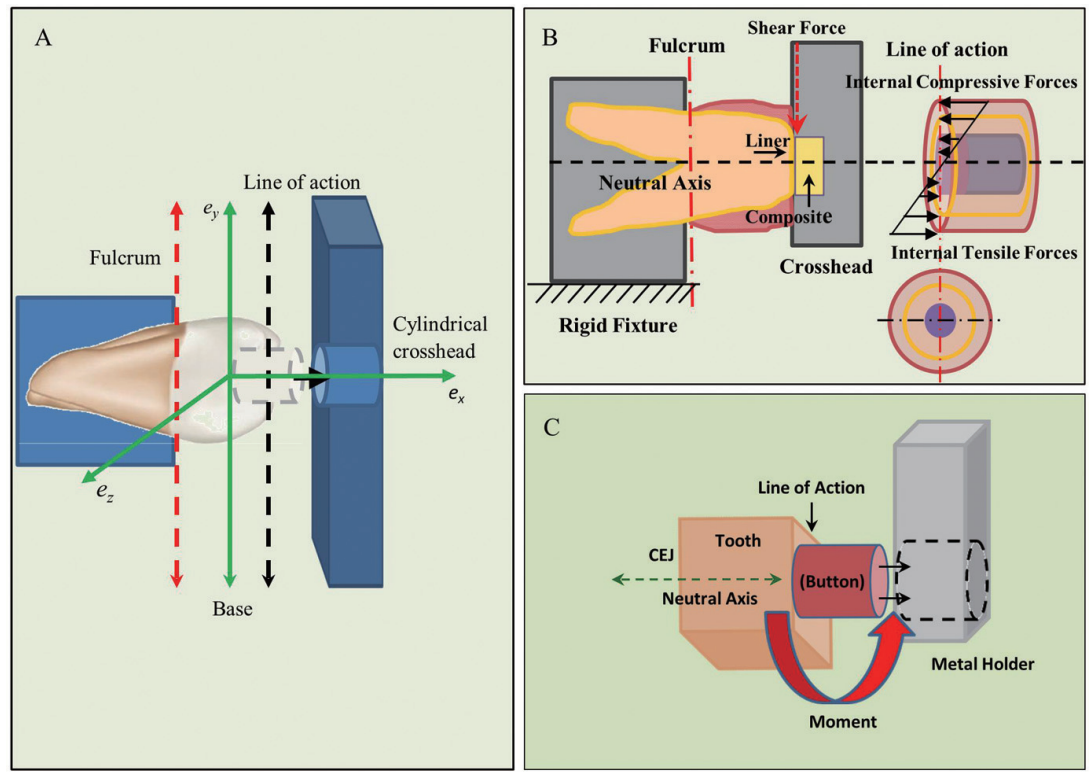

Fig. 6 (A) Lateral forces acting on a tooth will generate tension in the cervical region on one side, while generating compressive stress on the opposite side. The magnitude of these forces on the cervical region depends not only on the magnitude and direction of the lateral forces but also on the distance to their application in relation to the base of the tooth, due to the fulcrum effect. (B) Any force on the restoration produces compression, tension or shear along the tooth/restoration interface, leading to complex stress distributions; a combination of compressive, tensile and shear stresses. (C) Applying tensile force accurately along the plane gives rise to configurations that minimize distortion away from the plane. The offset metal holders suspend the restored teeth bucco-lingually in a horizontal position and center the line of action to the specified adhesive layer of the restored tooth. 
homogenously along the plane. This is accomplished by using vice grips to hold each end of the sample and applying a tensile force at a controlled rate and which is proportional to the entire adhesive surface area ${ }^{31}$.

The cylindrical crosshead used in this study applied the load homogenously along the plane of the composite adhesive layer. Distributed loading produced both tension and compression which then transferred from the material to the surrounding tissues (Fig. 3). This was validated by FEA, after measuring the bond strength of a composite button bonded to a $7.06 \mathrm{~mm}^{2}$ surface area on the occlusal surface of extracted mandibular molars ${ }^{21)}$. Sano et al. ${ }^{14)}$ reported that with rectangular bonding areas between $0.25-11.65 \mathrm{~mm}^{2}$, tensile bond strength to dentin decreased as bonding area increased logarithmically. However, other investigators have also reported that smaller surface areas had significantly higher shear bond strength values compared to larger areas $^{32)}$. Given that the shear bond strength was $73 \%$ higher in our study compared to the results of the Shamrani study ${ }^{13)}$, despite an equivalent bonding area of $7.06 \mathrm{~mm}^{2}$ in both studies, our results may reflect the effect of a more homogeneous distribution of forces along the plane of the bond interface. With uniform distribution of stresses across the adhesive layer, the FEA at a minimum confirms that the cylindrical crosshead can be effectively used as an optional macro-shear test.

Yoshikawa et al. ${ }^{33)}$ reported that cavity configuration can influence resin bond strength to the dentin of class I cavity floors. They found that when the C-factor was increased by the creation of a three-dimensional cavity preparation, the bond strengths of composite resin could fall by as much as $35 \%$. They attributed the drop in bond strength and failure of the bond due to shrinkage stresses competing with resin-dentin bonds during the polymerization stage and to the premise that teeth with high C-factors may be more susceptible to polymerization shrinkage stress ${ }^{33)}$. Notwithstanding shrinkage stresses, other limitations of the micro-tensile bond test used by the authors may also have affected bond strengths. A relatively thicker adhesive layer in micro-shear tests, among other reasons, concentrates stresses which influence the maximum load, thereby rendering micro-tensile tests less accurate than shear tests $^{2}$. The shear load must also be applied precisely at the bonded interface to avoid subjecting the cylinder to rotation or bending rather than shear tension ${ }^{7,12}$. If the loading of force on the test slabs was not homogenously distributed, it may account for some of the drop in bond strength. Given these limitations, further investigation of the lap shear bond test using a cylindrical crosshead is merited as the model presented in this study may overcome these challenges.

It has been reported by some investigators that cavity shaped assembly designs that impart a very high configuration factor (the quotient of the bonded to the unbonded surface of a composite resin that shrinks due to polymerization) may have several advantages over common bond strength tests, including more realistic bond strengths ${ }^{20)}$. While it remains to be determined whether cavity shaped assembly designs actually yield more realistic bond strengths, FEA can provide further insight into the complex mechanical behavior of restored teeth by stress fields which are difficult to assess otherwise. Using the entire biomechanical unit as proposed in this study may help to evaluate the mechanical behavior of the restored tooth as a response variable and ultimately its impact on shear bond strength.

Many studies have investigated static loading of mandibular molars during mastication, notwithstanding that the masticatory forces acting on the teeth are constantly changing. In FEA studies examining the stresses induced in the first mandibular molar during mastication of morsels of various elastic moduli, the maximum pressure is generally exerted on the middle portion of the occlusal surface, causing high equivalent stress concentration in enamel on the lingual slope of the mandibular molar buccal cusp where contact occurred with the maxillary tooth ${ }^{34}$. In enamel, the stresses are located near the cementum-enamel junction (CEJ), while in dentin, the equivalent stresses occur in the cervical area, along the outer root surface below the CEJ, and along the pulp chamber. High equivalent stresses are generated in the occlusal enamel with compressive stresses predominantly appearing in the dentin along the $\mathrm{x}$-axis.

Our model evaluated shear bond strength of a composite-tooth interface while integrating the entire tooth into testing. Using the jig in this configuration allows further investigation of the mechanical behavior of the restored tooth as a response variable during shear bond testing. Although the model may not entirely reflect the conditions encountered intraorally, the distribution of major principal stress in the class I cavity configuration with the fulcrum set at the CEJ, is consistent with stress concentrations in the occlusal enamel and at the CEJ as expected to occur intraorally under function ${ }^{34)}$. In dentin, the stresses were distributed evenly in relation to the pulp chamber, with the highest equivalent stresses occurring in the occlusal enamel and in the cervical region of the lingual wall of the molar (Fig. 5).

In our calculations the maximum stresses were at the edge of the interface and they were equal to or lower than the normal compressive stresses. These localized areas of high tensile stresses presented as 'hot spots' at the corners of the base of the restoration in all of the FEA models. The high peak stresses at these hot spots' reaching values as high as $\pm 20 \mathrm{MPa}$ were likely caused by sudden changes in geometry at the base of the restoration, as sharp reentrant corners will often cause a 'singularity' in FEA simulations ${ }^{35}$. Although these tensile stresses depend on the position of the application of the load, they may obscure the shear stresses at the interface to initiate failure of the restoration at the surface of these hotspots and not at the interface. The FEA analysis may predict local stress concentrations in the interface, in order to relate the nominal strength to actual local stress achieved in the interface at the point 
of fracture ${ }^{8)}$ and, in turn, predict likely sites at which failure of the joint could be initiated.

For example, in real-life situations, it is impossible to produce an absolute right-angled corner at the joint between the tooth surface and the composite resin cylinder and a fillet of varying size will likely occur8). While the bond strength of dental bonding agents is determined by convention to be the value of nominal stress at failure load per unit area of bonded surface, the nominal stress can be attenuated by a critical stress that concentrates locally at the most vulnerable place, usually the edge of the bonded area. As explained by Van Noort $e t a l .^{8}$, if the aggregate stresses are well below the yield stress, the high stress zone would be confounded to a small area near the stress concentration. If the fillet is weak, then a crack may start in the fillet and propagate towards the region of high stress near the base of the interface. If the strength of the interface is sufficiently low, then the failure will begin at the interface in the region of maximum local stress. In these scenarios, FEA can give insight into the stress fields that would be impossible to assess otherwise and, consequently, predict where failure may be triggered at a place where there happens to be a defect of a critical size ${ }^{8)}$.

In summation, in modeling a planar shear bond test that uses a lap jig with cylindrical crosshead and evaluating the effects of a cylindrical crosshead on the stress distribution in the dentin adjacent to the compositedentin interface of a composite button restoration, FEA showed that stress were distributed homogenously across the adhesive layer. When the fulcrum was reset at the CEJ and the composite button was reconfigured as a class I cavity, localized stresses became increasingly concentrated at the occlusal margins of the restoration, where they could be tensile or compressive depending on the side of the restoration, reaching $\pm 20 \mathrm{MPa}$ under a $20 \mathrm{~N}$ vertical load application. At the bottom of the restoration (across the composite-dentin interface) stresses were lower, between $\pm 4-8 \mathrm{MPa}$ in dentin and $\pm 4-8 \mathrm{MPa}$ in the composite. The study showed that lap shear testing with a cylindrical crosshead is a feasible tool to measure shear bond strength of dental materials in lieu of wire-loop, chisel, knife-edged or notched crossheads, while using the entire biomechanical unit may be helpful to evaluate the mechanical behavior of the restored tooth as a response variable.

\section{CONCLUSION}

A cylindrical crosshead was proposed for shear bond strength testing of composite-tooth interfaces. A FEA showed that a cylindrical crosshead may distribute loading forces homogenously across restoration-tooth interfaces, while approximating more closely nominal strength values. Using the entire biomechanical unit may be helpful to evaluate the mechanical behavior of the restored tooth as a response variable. With uniform distribution of stresses across the adhesive layer, the FEA confirmed that a cylindrical crosshead can be effectively used as an optional macro-shear test.

\section{ACKNOWLEDGMENTS}

To Vera Stojanovska D.D.S., Ph.D. for assistance with shear testing. The authors have no conflict of interest.

\section{REFERENCES}

1) Nujella BPS, Choudary MT, Reddy SP, Kumar MK, Gopal T. Comparison of shear bond strength of aesthetic restorative materials. Contemp Clin Dent 2012; 3: 22-26.

2) Sirisha K, Rambabu T, Shankar YR, Ravikumar P. Validity of bond strength tests: A critical review: Part I. J Conserv Dent 2014; 17: 305-311.

3) Salz U, Bock T. Testing adhesion of direct restoratives to dental hard tissue -A review. J Adhes Dent 2010; 12: 343371.

4) Van Meerbeek B, Peumans M, Poitevin A, Mine A, Van Ende A, Neves A, De Munck J. Relationship between bond-strength tests and clinical outcomes. Dent Mater 2010; 26: e100-e121.

5) Braga RR, Meira JB, Boaro LC, Xavier TA. Adhesion to tooth structure: A critical review of "macro" test methods. Dent Mater 2010; 26: e38-e49.

6) De Munck J, Mine A, Poitevin A, Van Ende A, Van Meerbeek G. Testing bond strength. A review of the literature. Dent Mater 2010; 26: e139-e140.

7) Armstrong S, Geraldeli S, Maia R, Raposo LH, Soares CJ, Yamagawa J. Adhesion to tooth structure: A critical review of "micro" bond strength test methods. Dent Mater 2010; 26: e50-e62.

8) Van Noort R, Noroozi S, Howard IC, Cardew G. A critique of bond strength measurements. J Dent 1989; 17: 61-67.

9) Foong J, Lee K, Nguyen C, Tang G, Austin D, Ch'ng C, Burrow MF, Thomas DL. Comparison of microshear bond strengths of four self-etching bonding systems to enamel using two test methods. Aust Dent J 2006; 51: 252-257.

10) Sinhoretti MA, Consani S, De Goes MF, Sobrinho LC, Knowles JC. Influence of loading types on the shear strength of the dentin-resin interface bonding. J Mater Sci Mater Med 2001; 12: 39-44.

11) Pecora N, Yaman P, Dennison J, Herrero A. Comparison of shear bond strength relative to two testing devices. J Prosthet Dent 2002; 88: 511-515.

12) Tedesco TK, Garcia EJ, Soares FZM, Rocha RdeO, Grande RHM. Effect of two microshear test devices on bond strength and fracture pattern in primary teeth. Braz Dent 2013; 2: 605-609.

13) Shamrani ASA. An in-vitro assessment of micro-shear bond strength of a nano adhesive to dentin with different types of composite restorative systems. J Dent Health Oral Disord Ther 2016; 5: 00148.

14) Sano H, Shono T, Sonoda H, Takatsu T, Ciucchi B, Carvalho R, Pashley DH. Relationship between surface area for adhesion and tensile bond strength-evaluation of a microtensile bond test. Dent Mater 1994; 10: 236-240.

15) Phrukkanon S, Burrow MF, Tyas MJ. The influence of crosssectional shape and surface area on the microtensile bond test. Dent Mater 1998; 14: 212-221.

16) Abreu CW, Santos JFF, Passos SP, Michida SM, Takahashi FE, Bottino MA. The influence of cutting speed and cutting initiation location in specimen preparation for the microtensile bond strength test. J Adhes Dent 2011; 13: 221-226.

17) Raposo LH, Armstrong SR, Maia RR, Qian F, Geraldeli S, Soares CJ. Effect of specimen gripping device, geometry and fixation method on microtensile bond strength, failure mode and stress distribution: laboratory and finite element analyses. Dent Mater 2012; 28: 50-62.

18) Watanabe LG, Marshall Jr GW, Marshall SJ. Dentin shear strength: Effects of tubule orientation and intratooth location. 
Dent Mater 1996; 12: 109-115.

19) Pinzon LM, Watanabe LG, Reis AF, Powers JM, Marshall SJ, Marshall GW. Analysis of interfacial structure and bond strength of self-etch adhesive systems. Am J Dent 2013; 26 : 335-340.

20) Schneider BT, Baumann MA, Watanabe LG, Marshall Jr GW. Dentin shear bond strength of compomers and composites. Dent Mater 2000; 16: 15-19.

21) Stojanovska V, Ivanoff CS, Muratovska I, Filipovska L, Garcia-Godoy F, Hottel TL, Marković DLj, Morrow B. Joggle lap shear testing of deep occlusal composite restorations lined with Dycal, Dycal Lc, conventional or resin-modified glass ionomer. Vojnosanit Pregl 2017; 74: 410-419.

22) Sakaguchi RL, Powers JM. Craig's restorative dental materials. 13th ed. Philadelphia: (Elsevier) Mosby; 2012.

23) Timoshenko S, Gere JM. Mechanics of materials. 1st ed. New York: Van Nostrand Reinhold Company; 1972.

24) Zhang YR, Du W, Zhou XD, Yu HY. Review of research on the mechanical properties of the human tooth. Int J Oral Sci 2014; 6: 61-69.

25) Chung SM, Yap AUJ, Tsai KT, Yap FL. Elastic modulus of resin-based dental restorative materials: A microindentation approach. J Biomed Mater Res B Appl Biomater 2005; 72: 246-253.

26) Chung SM, Yap AU, Koh WK, Tsai KT, Lim CT. Measurement of Poisson's ratio of dental composite restorative materials. Biomaterials 2004; 25: 2455-2460.

27) Hassan AM, Goda AA, Baroudi K. The effect of different disinfecting agents on bond strength of resin composites. Int
J Dent 2014; ID 231235.

28) Ilie N, Schöner C, Bücher K, Hickel R. An in-vitro assessment of the shear bond strength of bulk-fill resin composites to permanent and deciduous teeth. J Dent 2014; 42: 850-855.

29) Flury S, Peutzfeldt A, Lussi A. Influence of increment thickness on microhardness and dentin bond strength of bulk fill resin composites. Dent Mater 2014; 30: 1104-1112.

30) Braz R, Sinhoreti MA, Spazzin AO, Loretto SC, Lyral AM, Meira-Júnior AD. Shear bond strength test using different loading conditions — a finite element analysis. Braz J Oral Sci 2010; 9: 439-442.

31) Mecmesin. Lap shear testing [Internet]. 2017 [cited March 3, 2017]. Available from: http://www.mecmesin.com/lap-sheartesting.

32) El-Askay FM, Nassif MS, Andrade AM, Reis A, Loguercio AD. Effect of surface area and air drying distance on shear strength of etch-and-rinse adhesive. Braz Oral Res 2012; 26: 418-423.

33) Yoshikawa T, Sano H, Burrow MF, Tagamil J, Pashley DH. Effects of dentin depth and cavity configuration on bond strength. J Dent Res 1999; 78: 898-905.

34) Dejak B, Młotkowski A, Romanowicz M. Finite element analysis of stresses in molars during clenching and mastication. J Prosthet Dent 2001; 86: 650-654.

35) Sönnerlind H. Singularities in finite element models: dealing with red spots [Internet]. 2015 [cited March 20, 2017]. Available from: https://www.comsol.com/blogs/singularitiesin-finite-element-models-dealing-with-red-spots/. 